\title{
Normative Gaps between Communities and Collective Identities in Governing Cultural Heritage: An Argument on How to Apply Hobbesian and Lockean Theories to Restore the Political Dignity of Communities in Their Role to Safeguard Cultural Heritage
}

Oana Șerban ${ }^{1}$

\section{Introduction: Communities and collective identities regarded from the standpoint of subjective rights and intersubjective relationships}

This research deals with the conflict between individual and collective identities as shareholders in heritage processes, from a normative standpoint. Therefore, my objective is to explore the genealogy of the subjective rights developed by collective identities in governing and managing cultural heritage. As the notion of cultural heritage is fostered by the correspondent value that an explicit (hence tangible) or implicit (thus intangible) form of patrimony expresses and represents for a certain community, we tend to treat collective agents - communities, societies as shareholders that accept and internalise such values in terms of an imaginary community, meaning a projected social body emergent to such axiological constructs. The values assigned to a specific form of cultural heritage must count both for each individual of a community and for the collective identity reflected by that community. At a first glimpse, individual and collective identities should not fall under a conflict in terms of cultural heritage, at least not in what concerns the axiological adhesion of each of them to a certain value structurally represented by a form of cultural heritage. Methodologically, such an argument might

${ }^{1}$ University of Bucharest, Faculty of Philosophy, Romania. 
raise the impression that holistic approaches should be rather privileged in contemporary debates on governing cultural heritage, but that is a trap. Individualism counts as much as holism in the framework of a comprehensive view on internalising values of cultural heritage and embodying individual values to the collective consciousness of a community that holds a specific form of cultural heritage. Consequently, following Groth, I will try to sum up the clash between individual and collective axiological constructs identifying normative gaps that arise from their contrast in different processes of governing cultural heritage, such as "propertization" or "heritagization"?

\section{The multiple and ambiguous normative meanings of communities as shareholders of cultural heritage}

As Groth argues, "heritage is a common social process that gains its characteristics from its reference to shared experience and its specific perception of a subjective stance."3 Such a definiendum implies at least the following three presuppositions:

(1) In any process of essentializing culture in order to point out the core-values specific to a certain community and reflected by its cultural heritage, the collective identity of such community is projected as a superordinated notion to that of individual identity. Therefore, collective values are superordinated to individual values and somehow segregated.

(2) Governing cultural heritage means addressing collectivelybased rights to collective identities that recognize, hold and protect their representative cultural heritage. One possible emergent conflict from this holistic outlook on cultural heritage is that between individual and collective rights in governing cultural heritage.

(3) Cultural heritage lies on a specific form of recognition that evaluates specific core-values of specific forms of cultural heritage

\footnotetext{
2 S. Groth, "Between Society and Culture: Recognition in Cultural Heritage Contexts," in Between Imagined Communities of Practice: Participation, Territory and the Making of Heritage, eds. Nicolas Adell, Regina F. Bendix, Chiara Bortolotto, et al. (Göttingen: Göttingen University Press, 2015), 59.

${ }^{3}$ S. Groth, "Between Society and Culture: Recognition in Cultural Heritage Contexts," 61.
} 
embodied by a community. As an axiological process, this recognition practice follows the model of an intersubjective interaction. Despite the social and cultural dynamics of a society, these core-values must be maintained in order to keep unsalted the forms of cultural heritage.

Groth's question, "are there any false conflicts in heritage research?"4 is more than a sharp and critical interrogation addressed to any practitioner from this domain. He considers that there are several dynamics that cross the evolution of a community, from the transformation of "cultural artifacts and practices", to the "attributions of value and power to actors in the field of heritage" 5 , but that any normative and factual conflict that emerges from these particular conditions can be solved by advancing the notion of intersubjectivity into "heritage debates" and processes.

First of all, Groth's argument is inspired by the assumption that cultural heritage is a notion tributary to communities. It expresses shared cultural practices and properties that are preserved, restored and governed by communities or representative groups. There through, "the common view is that heritage is based on collectivities, and that the power of heritage rests on collective memory and identity." 6 Genealogically, a form of cultural heritage must be constituted within a community, must be representative for that community and, finally, is administrated in a collective framework by a collective agency. Cultural heritage develops collective rights that must be conciliated between the legal shareholder of a specific form of patrimony and the representative collective agencies of such form of patrimony - in this latter acceptation, bumanity is the largest collective structure that calls for the paternity and responsibility of cultural heritage. But what are the main understandings of "communities" and "individuals", both constitutively and normatively, in the current policies of safeguarding cultural heritage? The UNESCO conventions are illustrative from this standpoint.

\footnotetext{
4 Idem, 62.

${ }^{5}$ Ibidem.

${ }^{6}$ Ibidem.
} 
Let us take, for example, a look to the legal terms of the Convention for the Safeguarding of the Intangible Cultural Heritage ${ }^{7}$. Its grounds are inspired by actions such as "recognizing that the processes of globalization and social transformation, alongside the conditions they create for renewed dialogue among communities", "recognizing that communities, in particular indigenous communities, groups and, in some cases, individuals, play an important role in the production, safeguarding, maintenance and re-creation of the intangible cultural heritage, thus helping to enrich cultural diversity and human creativity," or "considering that the international community should contribute, together with the States Parties to this Convention, to the safeguarding of such heritage in a spirit of cooperation and mutual assistance."8

As experts of UNESCO recognize by themselves, "communities" and "groups" are addressed non-specifically. They are depicted as shareholders of "tradition-bearers", determined by "an open character, not necessarily linked to specific territories". This atopic character can raise multiple problems in recognizing and governing cultural heritage. Albeit communities are not restricted to a certain territory, reflecting a dynamic, unterritorialized space for manifesting, elements of intangible cultural heritage are identifiable between borders, "present in their territory". Individuals appear as vehicles of transmitting cultural heritage, along with communities and groups, in terms of board cooperation. In this sense, individuals and groups are part of a certain generation, whereas the intangible cultural heritage of a community borrows the aspect of a living culture that is handed down from generation to generation.

According to Groth,

the acknowledgement of collective cultural innovation and creation by "indigenous and local communities" or

\footnotetext{
7 "Text of the Convention for the Safeguarding of the Intangible Cultural Heritage." The General Conference of the United Nations Educational, Scientific and Cultural Organization hereinafter referred to as UNESCO, meeting in Paris, from 29 September to 17 October 2003, at its 32nd session. https://ich.unesco.org/en/convention (accessed December 1st, 2019).

8 Ibidem.

9 "Involvement of communities, groups and individuals", in Safeguarding Intangible Cultural Heritage, UNESCO, 2003. https://ich.unesco.org/en/involvement-of-communities00033 (accessed December 1st, 2019).
} 
"communities [and] groups" is discussed and promoted by conventions. However, the central term - "community" indicates the wariness of states to make more substantial concessions to the sovereignty and autonomy of these groups. The term indexes their weak legal position regarding the distribution and administration of rights to cultural property (Socha 2013). Communities are not clearly defined as legal entities capable of holding rights. ${ }^{10}$

By this, we get to one of the most important problems of this article: how can we foster communities not only culturally constitutive and responsible, but also legally? Their identity is socially blended: cultural determinations are developed as a set of concepts, values, beliefs, values and possessions that do not reflect the natural state of a community, but its artificial evolution. Heritagization should raise the opportunity for communities to self-represent, to become politically enrolled in the process of governing cultural heritage as a direct agent. As a consequence, we deal with the following problematic context in advancing communities as legal, responsible collective identities enrolled in governing cultural heritage:

(1) There is no specific framework of analyzing the political utility of communities as legally responsible for forms of cultural heritage.

(2) Collective identities assigned to communities involve collective rights and normative implications of cultural heritage as property based on collective identities.

(3) Genealogically, especially in an essentialist paradigm, culture needs collective rights since the notion of culture is exclusively relative to a community.

(4) Introducing collective rights of culture imposes the conceptual shift from personhood to peoplehood in terms of agents of property.

\footnotetext{
10 S. Groth, "Between Society and Culture: Recognition in Cultural Heritage Contexts," 63. The author refers to P. Socha, "Spielräume im Völkerrecht: Regional differierende Interpretationen der 'Begünstigten' in den draft articles des WIPO IGC,' in Kultur_Kultur. Denken, Forschen, Darstellen. 38. Kongress der Deutschen Gesellschaft für Volkskunde in Tübingen vom 21. bis 24. September 2011, eds. Reinhard Johler, Christian Marchetti, Bernhard Tschofen, and Carmen Weith (Münster: Waxmann, 2013), 96-106.
} 
(5) Cultural heritage is remarkable and identifiable in a context of scarcity addressed to those objects, practices or values that determine a specific form of enunciated cultural heritage. To analyze scarcity, boundaries are needed.

(6) Communities are designed as necessary platforms for future emerging societies.

Groth argues that "communities are not conceptualized as social entities with a priori legitimization and practices or artifacts bound to their essence." 11 However, the identity framework, in terms of Habermas ${ }^{12}$, is the same for communities and societies: they represent spheres of our living world, in which values that reflect their individuality raise and transgress historicity, preserving a certain authenticity. However, as communities reveal to be necessary but not sufficient for the constitution and preservation of cultural heritage, so does the state by revealing useful but not omnipotent in controlling the transmission and reproduction of cultural heritage. In fact, for Habermas, cultural heritage, in its constitution and transmission, is one of the many results that the liberty of a community and the autonomy of its individuals perform.

Cultural heritages and the forms of life articulated within them normally reproduce themselves by convincing those whose personality structures they shape, that is, by motivating them to appropriate and continue the traditions productively. The constitutional state can make this hermeneutic achievement of the cultural reproduction of worlds possible, but it cannot guarantee it. For to guarantee cultural survival would necessarily rob the members of the freedom to say yes or no, which nowadays is crucial if they are to remain able to appropriate and preserve their cultural heritage. ${ }^{13}$

\footnotetext{
11 S. Groth, "Between Society and Culture: Recognition in Cultural Heritage Contexts," 69. 12 J. Habermas, "Human Rights: Global and Internal," in The Inclusion of the Other. Studies in Political Theory, eds. C. Cronin and P. De Greiff (Cambridge: Polity Press, 1998), 222. See J. Habermas, The Theory of Communicative Action, Vol. I. (Boston: Beacon Press, 1984). J. Habermas, The Theory of Communicative Action, Vol II (Boston: Beacon Press, 1987).

13 J. Habermas, "Human Rights: Global and Internal," 222.
} 
Groth quotes Habermas in order to convince that cultural heritage imposes subjective rights and that once this hypothesis is accepted, then cultural heritage must be tracked as cotangential element with isolated interests claimed by individuals. Isolated interests do not exclude convergent interests. The welfare of a community represents a common interest. As a matter of fact, the preservation, reproduction and transmission of cultural heritage should be judged both through the lens of individual and collective interests, therefore, both through the lens of subjective and intersubjective rights. In order to support the thesis of normative gaps between individuals and communities as agencies of governing cultural heritage, Groth invokes after Habermas the theory of recognition that belongs to Honneth. In short, this theory argues that there are three forms of recognition, one reflected by primary relationships based on affective mutual recognition, one represented by legal grounds, based on laws as mutual recognition of the individuals' freedom, equality and actions, and one designed as social appreciation or solidarity, through which individuals empathize in terms of a shared system of values raised in a certain society, for which "a cultural selfconception is needed - Wertgemeinschaft (Honneth 1994: 198) - which is exactly why the notion of cultural heritage needs to be related to social dynamic" 14 . Albeit Honneth's objective is to explain how individual interests affect heritage processes in terms of exploiting through commerce different forms of cultural heritage, Groth saves from such a theory the community regarded as "communal achievement" 15 . In short, individuals have subjective rights through which they exercise the option to practice a certain tradition or to preserve it, but they also have the right to adhere to a collective identity. Social appreciation becomes the fundamental values on which the interaction of individuals is focused and from which the possibility of heritage as particular entity that reveals those proper practices to a collective identity/community through which it differentiates from other communities is raised. The same sense of solidarity that works for social inclusion is restored in Anderson's theory on imagined communities. In his opinion, a nation can be tracked as "an imagined political community", whereas "imagined" stays as a proper

14 S. Groth, "Between Society and Culture: Recognition in Cultural Heritage Contexts," 73. See also A. Honneth, Kampf um Anerkennung: zur moralischen Grammatik sozialer Konflikte (Frankfurt am Main: Suhrkamp, 1994).

15 S. Groth, "Between Society and Culture: Recognition in Cultural Heritage Contexts," 76. 
determination "because the members of even the smallest nation will never know most of their fellow-members, meet them, or even hear of them, in the minds of each lives the image of their communion"16. The same argument works for communities culturally-based in terms of heritage: no contemporary agent has any contact with his historical ancestors excepting the intangible or tangible form of culture inherited. Nations are communities as long as they are large social entities grounded on solidarity and comradeship, despite all the natural and artificial inequalities between individuals. More than ever, for Anderson, nationalism must gain in front of cosmopolitanism: collective individualities must win in front of individual collectivities. Consequently, Anderson's theory might of high use for those who work in the field of cultural heritage: communities are social bodies depicted abstractly, by associating generations that have no access to one another otherwise than through a common nucleus, reflected by the representative cultural heritage. So, community is a win for ensuring the empathy between individuals who compose a society or a nation that claims the status of shareholder for a cultural heritage. And yet, it is not enough to solve the legal responsibility and status that we have previously identified as lacunar or even absent. Nations are more related to patriotism than to statist constructs. However, imagined communities as nations require an individual, legal treatment and recognition.

\section{In search of a "political" dignity: how to solve the tension between collective identities and communities?}

One possible way out of this normative conflict between collective identity and community enrolled as shareholders of cultural heritage might be represented by modern theories of social contract that discuss individual and common properties in terms of commonwealth. Hobbes, in his Leviathan, explains that the notions of "fairness" and "unfairness" have no coverage in the context of natural state, but once they are related to the social contract, they gain validity and can morally and legally qualify the mechanisms of converting possessions to properties.

16 B. Anderson, Imagined communities: reflections on the origin and spread on nationalism (London: Verso, 1991), 6. 
For where there is no Commonwealth, there is, as hath been already shown, a perpetual war of every man against his neighbour; and therefore everything is his that getteth it and keepeth it by force; which is neither propriety nor community, but uncertainty. ${ }^{17}$

Cultural heritage could be addressed, by renewing Hobbesian perspectives, as properties that must be shared with our community: it is therefore distributed through the terms of a social contract, meaning by conventions, agreements, exchanges. A powerful Commonwealth is constructed not only by individual, material properties, but also by useful arts that emerge from natural possessions, from language, affects, values, principles. Implicitly, a Commonwealth is raised on all those material and intangible elements that are shared by individuals in the name of their welfare and under the conditions of the social contract that reflects them as a community.

Further, seeing it is not enough to the sustentation of a Commonwealth that every man have a propriety in a portion of land, or in some few commodities, or a natural property in some useful art, and there is no art in the world but is necessary either for the being or well-being almost of every particular man; it is necessary that men distribute that which they can spare, and transfer their propriety therein mutually one to another by exchange and mutual contract. ${ }^{18}$

Moreover, Locke's amendments to the Hobbesian theory on social contract and private property can be used as corrective instruments in evaluating the future role of communities and their tensions with the notion of collective identities in governing cultural heritage.

According to Locke,

(28) When there is some land that has the status of a common-being held in common by the community by agreement among them — taking any part of what is common

\footnotetext{
17 T. Hobbes, "Chapter XXIV. Of The Nutrition and Procreation of a Commonwealth", in Leviathan, Or The Matter Forme and Power Of A Commonwealth Ecclesiastical And Civil (Australia: The University of Adelaide Library, 2016). https://ebooks.adelaide.edu.au/ h/hobbes/thomas/h68l/index.html (accessed at December 1st, 2019).

18 Ibidem.
} 
and removing it from the state nature leaves it in creates ownership; and if it didn't, the common would be of no use. And the taking of this or that part doesn't depend on the express consent of all the commoners [ $=$ 'all those who share in the common ownership of the land']. ${ }^{19}$

Cultural heritage could be regarded as common ownership. As any tangible form of cultural heritage is the result of a work that lies at the core of any property, so does intangible cultural heritage fall under the incidence of common efforts that individuals inscribe in their activities of leaving the natural state behind and entering into a community. On the other hand, Locke explicitly saves the political authority of a community, that seems to be neglected by contemporary theories or conventions on the role of communities in safeguarding cultural heritage.

99. So those who out of a state of nature unite into a community must be understood to give up all the power required to secure its purposes to the majority of the community (unless they explicitly agree on some number greater than the majority). They achieve this simply by agreeing to unite into one political society; that's all the compact that is needed between the individuals that create or join a commonwealth." 20

Therefore, Locke refers to the end of the state of nature, which is a metaphysical abstraction, in its highest accuracy, as the inauguration of a community that will rule through a majority and that will unite individuals into a political body which is enough to proclaim a commonwealth. The distinction between community and commonwealth is not quite clear, as Culea explains. The commonwealth cannot exist in the absence of governance, but multiple communities can adhere to a commonwealth. Collectivity is recommended by translators of the Lockean oeuvre, such as Culea, as an intermediary phase between the natural state and the community ${ }^{21}$. The reason for this interpretation

${ }^{19}$ J. Locke, The Second Treatise of Government (Indianapolis: Hackett Publishing, 1690).

20 Ibidem.

21 See S. Culea, "Notes regarding the translation of terms" in J. Locke, Al doilea tratat despre cârmuire. Scrisoare despre toleranță (The Second Treatise of Government) (Bucharest: Nemira, 1999), 45. 
lies on the following Lockean remark, that wherever there is a law, people represent a collectivity, meaning that the natural state, based on natural laws, could be inscribed in the pattern of a collectivity. But the major advantage of Locke's theory is that communities gain political legitimacy in protecting common ownership on properties and this argument could be invested in saving the political role of communities in safeguarding cultural heritage, or at least to clarify their political status which is, as we have previously observed in the UNESCO's Conventions, unclear.

\section{Conclusions}

The purpose of this article was to identify the normative tensions between collective identities and communities as shareholders of cultural heritage. A specific analysis of UNESCO's conventions of safeguarding cultural heritage reveals that communities have an ambiguous political role in governing cultural heritage but they are recognized as equal entities with individuals and groups in preserving, restoring and transmitting cultural heritage. A brief sketch on the multiple modern uses of "community" reveal their political potential and the implications that such meanings have in fixing a certain acceptation of "collective identity" behind tangible and intangible forms of cultural heritage. Hobbesian and Lockean theories on the genealogy and evolution of community, collectivities and commonwealth are more actual than ever in the terms of this analysis and ultimately prove a great potential in solving the dilemmas raised by the political responsibility that communities should claim in performing their role of governing cultural heritage.

\section{References}

Anderson, Benedict. Imagined communities: reflections on the origin and spread on nationalism. London: Verso, 1991.

Culea, Silviu. "Notes regarding the translation of terms." In J. Locke, $A l$ doilea tratat despre cârmuire. Scrisoare despre toleranță (The Second Treatise of Government), 45-8. Bucharest: Nemira, 1999.

Groth, Stefan. "Between Society and Culture: Recognition in Cultural Heritage Contexts." In Between Imagined Communities of Practice: Participation, Territory and the Making of Heritage, eds. Nicolas Adell, Regina F. Bendix, Chiara Bortolotto, et al. 59-81. Göttingen: Göttingen University Press, 2015. 
Habermas, Jürgen. "Human Rights: Global and Internal." In The Inclusion of the Other. Studies in Political Theory, eds. C. Cronin and P. De Greiff. Cambridge: Polity Press, 1998.

—. The Theory of Communicative Action, Vol II. Boston: Beacon Press, 1987. —. The Theory of Communicative Action, Vol. I. Boston: Beacon Press, 1984. Hobbes, Thomas. "Chapter XXIV. Of the Nutrition and Procreation of a Commonwealth." In Leviathan, Or the Matter Formed and Power of a Commonwealth Ecclesiastical and Civil. Australia: The University of Adelaide Library, 2016. https://ebooks.adelaide.edu.au/h/hobbes/ thomas/h68l/index.html (accessed at December 1st, 2019).

Locke, John. The Second Treatise of Government. Indianapolis: Hackett Publishing, 1690.

\section{Online sources}

"Text of the Convention for the Safeguarding of the Intangible Cultural Heritage." The General Conference of the United Nations Educational, Scientific and Cultural Organization hereinafter referred to as UNESCO, meeting in Paris, from 29 September to 17 October 2003, at its 32nd session. https://ich.unesco.org/en/convention

"Text of the Convention for the Safeguarding of the Intangible Cultural Heritage." The General Conference of the United Nations Educational, Scientific and Cultural Organization hereinafter referred to as UNESCO, meeting in Paris, from 29 September to 17 October 2003, at its 32nd session. https://ich.unesco.org/en/convention "Involvement of communities, groups and individuals". In Safeguarding Intangible Cultural Heritage, UNESCO, 2003. https://ich.unesco .org/en/involvement-of-communities-00033

\section{Acknowledgements}

This article is supported by research project "Identity Architectures and New Categories of Cultural Heritage: A Multidisciplinary Analysis of the Mechanisms of Constructing Identities Regarding the Cultural Heritage of Contemporary Romania” PN III-P1-1.2-PCCDA-2017-0686, 52PCCDI/2018 and by the research project "Entrepreneurial education and professional counselling for doctoral and postdoctoral researchers in transferring knowledge from the field of social and humanist sciences to the labour market" POCU/380/6/13/123343. 